\title{
The relationship between glycaemic variability and cardiovascular autonomic dysfunction in patients with type 1 diabetes: a systematic review
}

\author{
S. Helleputte ${ }^{1} \cdot$ T. De Backer ${ }^{2}$ B. Lapauw ${ }^{3} \cdot$ S. Shadid ${ }^{3} \cdot$ B. Celie ${ }^{1} \cdot$ B. Van Eetvelde ${ }^{1} \cdot$ K. Vanden Wyngaert ${ }^{1} \cdot$ P. Calders $^{1}$ \\ ${ }^{1}$ Department of Rehabilitation Sciences, Faculty of Medicine and Health Sciences, Ghent University, Belgium. \\ 2 Department of Cardiology, Ghent University Hospital, Belgium. \\ ${ }^{3}$ Department of Endocrinology, Ghent University Hospital, Belgium.
}

Corresponding author:

Helleputte Simon

Ghent University

Corneel Heymanslaan 10,

Ghent 9000, Belgium

Telephone: +32 (0) 93323627

E-mail: Simon.Helleputte@ugent.be

ORCID ID: https://orcid.org/0000-0003-3281-1679

Word count: 4174 (Introduction + Methods + Results + Discussion - excluding Tables and References)

Systematic review registration number - PROSPERO: CRD42019117863.

Protocol accessible via the following URL:

http://www.crd.york.ac.uk/PROSPERO/display record.php?ID=CRD42019117863

The PROSPERO protocol is also added as supplementary material alongside this submission.

This article has been accepted for publication and undergone full peer review but has not been through the copyediting, typesetting, pagination and proofreading process which may lead to differences between this version and the Version of Record. Please cite this article as doi: 10.1002/dmrr.3301 


\section{ABSTRACT}

Rigorous glycaemic control - reflected by low HbA1c goals - is of utmost importance in the prevention and management of complications in patients with type 1 diabetes mellitus (T1DM). However, previous studies suggested that short-term glycaemic variability (GV) is important to consider as well, as excessive glucose fluctuations may have an additional impact on the development of diabetic complications. The potential relationship between GV and the risk for cardiovascular autonomic neuropathy (CAN), a clinical expression of cardiovascular autonomic dysfunction, is of increasing interest. This systematic review aimed to summarize existing evidence concerning the relationship between GV and cardiovascular autonomic dysfunction in T1DM. Electronic database search of Medline (Pubmed), Web of Science and Embase was performed, up to October 2019. There were no limits concerning year of publication. Methodological quality was evaluated with the Newcastle Ottawa Scale for observational studies. Six studies (four cross-sectional and two prospective cohorts) were included. Methodological quality of the studies varied from level C to A2. Two studies examined the association between GV and heart rate variability (HRV) and both found significant negative correlations. Regarding cardiovascular autonomic reflex tests (CARTs), two studies did not while two other studies did find significant associations between GV parameters and CART-scores. However, associations were attenuated after adjusting for covariates such as HbA1c, age and disease duration. In conclusion, this systematic review found some preliminary evidence supporting an association between GV and cardiovascular autonomic dysfunction in T1DM. Hence, uncertainty remains whether high GV can independently contribute to the onset or progression of CAN. The heterogeneity in methodological approach made it difficult to compare different studies. Future studies should therefore use uniformly evaluated CGM-derived parameters of GV, while standardised assessment of HRV, CARTs and other potential cardiac autonomic function parameters is needed for an unambiguous definition of CAN.

KEYWORDS Type 1 diabetes - Complications - Glycaemic variability · Cardiovascular autonomic dysfunction . Cardiovascular autonomic neuropathy · Cardiovascular reflex tests · Heart rate variability

\section{ABBREVIATIONS}


BRS

Baroreflex sensitivity

CAN Cardiovascular autonomic neuropathy

CART Cardiovascular autonomic reflex test

CGM Continuous glucose monitoring

CONGA Continuous overlap net glycaemic action

COV Coefficient of variation

DAN Diabetic autonomic neuropathy

DCCT Diabetes Control and Complications Trial

GV Glycaemic variability
HBGI High blood glucose index

HRV Heart rate variability

LBGI Low blood glucose index

MBG Mean blood glucose

MAG Mean absolute glucose difference

MAGE Mean amplitude of glycaemic excursions

MODD Mean of daily differences

$\mathrm{SD}_{T} \quad$ Total standard deviation of glucose values

T1DM Type 1 diabetes mellitus

\section{RESEARCH IN CONTEXT BOX}

What is already known?

- Short-term glycaemic variability (GV) is an integral component of glucose homeostasis in patients with type 1 diabetes (T1DM), next to HbA1c as a long-term measure of glycaemic control.

- In-depth assessment of these blood glucose fluctuations is of increasing interest in latest years since previous research suggested a role in the development of diabetic complications.

- Cardiac autonomic neuropathy is associated with higher morbidity and increased CVD mortality in type 1 diabetes and assessment of heart rate variability and cardiovascular autonomic reflex function can be used as early screening strategies.

What is the key question?

- Does higher glycaemic variability independently contribute to the development of cardiovascular autonomic dysfunction in type 1 diabetes?

What are the new findings?

- High short-term GV might negatively affect heart rate variability (HRV).

- The impact of GV on cardiovascular autonomic reflex function is less certain.

Possible impact on clinical practice in the future?

- Increasing attention should be pointed towards a glycaemic management that goes beyond HbA1c, aiming at a stable glucose homeostasis with less glycaemic fluctuations as it could be crucial in avoiding the vicious circle of deteriorating autonomic function, recurrent hypoglycaemia and its consequences. 
However, there is an urgent need of more research concerning this matter, preferably long-term prospective studies.

\section{INTRODUCTION}

Strict glycaemic follow-up is of utmost importance in type 1 diabetes (T1DM) management to prevent or delay the onset of diabetic complications. Since chronic hyperglycaemia remains the main determinant of these complications, as proven by the Diabetes Control and Complications Trial (DCCT) ${ }^{1}, \mathrm{HbA} 1 \mathrm{c}$ is still considered as the gold-standard measure of glycaemic control with a primary target to lower HbA1c as much as safely possible 2 . However, even if patients display similar HbA1c values and mean blood glucose, their glucose profiles may greatly fer $^{3}$. The importance of these short-term fluctuations is of increasing interest in the past decade, which has led to a new concept: glycaemic variability (GV), a term referring to intra- and inter-day glycaemic fluctuations ${ }^{3-6}$.

Concerning the methods to assess GV, older studies used 7-point capillary blood glucose profiles. Nowadays, continuous glucose monitoring (CGM) is considered as the number one method for the determination of short-term GV, with numerous metrics that have been established yet ${ }^{3,7}$. GV is generally subdivided in withinday and inter-day variability ${ }^{3,7,8}$. To reflect within-day GV, total standard deviation (SDT), coefficient of variation (COV\%) and mean amplitude of glucose excursions (MAGE) are recommended and most widely used, while the mean of daily differences (MODD) has been suggested to reflect between-day variability ${ }^{7,8}$. Besides, these measures can be complemented with the high and low blood glucose index (HBGI, LBGI), taking separately into 
account the risk for hypo- and hyperglycaemic events ${ }^{9}$. Other metrics have also been proposed but are rarely used $^{7,10-14}$

The role of GV in the development of diabetic complications is of increasing interest and should not be underestimated $^{15-18}$, as some studies indicated that GV could independently contribute to microvascular complications ${ }^{19-21}$. A well-known complication is diabetic autonomic neuropathy (DAN), which affects the autonomic nervous system. Regarding the latter, damage to autonomic nerve fibres innervating heart and blood vessels can result in cardiovascular autonomic neuropathy (CAN), an important yet still underestimated problem ${ }^{22,23}$. Pathogenesis of CAN is complex, multifactorial and still under debate. Prevalence was reported to be between $15-35 \% 23,24$ and the most important risk factors include diabetes duration, high HbA1c and the conventional CV risk factors (hypertension, hyperlipidaemia and smoking) ${ }^{23-25}$. Clinical manifestations of CAN may range from latent signs such as nocturnal hypertension with non-dipping ${ }^{26}$ to signs of resting tachycardia, exercise intolerance and more severe signs such as orthostatic hypotension, ECG abnormalities or even silent myocardial infarction 22,24,27. Detection of CAN is crucial as it is associated with high morbidity and mortality ${ }^{27-29,}$ and can be evaluated by simple non-invasive methods: analysis of heart rate variability (HRV), cardiovascular reflex tests (CARTs) or baroreflex sensitivity (BRS) ${ }^{22,23,27,30}$.

Some researchers suggested that GV may independently contribute to neuronal damage leading to the development of CAN. While studies in T2DM have already indicated that GV might influence cardiovascular autonomic function ${ }^{31-34}$, the evidence in T1DM is scarce. Given the previous research and gaps in existing literature, the purpose of this systematic review was to review the current evidence on the relationship between existing parameters of GV and cardiovascular autonomic dysfunction in patients with T1DM.

\section{METHODS}

This review was written according to the international PRISMA guidelines for reporting systematic reviews ${ }^{35}$.

\section{Eligibility criteria}

All studies that examined the association between parameters of GV and cardiovascular autonomic function in patients with T1DM were included (PICOS format). No restrictions were applied for age or disease duration of the patient population. All parameters used in current literature to express a degree of GV were accepted ${ }^{3,6}$. Considering cardiovascular autonomic function, several outcomes could be reported (HRV, CARTs,...). Articles could be written in English, French or Dutch and no limits were used concerning publication year of eligible studies. 


\section{Information sources and search strategy}

Studies were identified by electronic database search of Medline (PubMed), Web of Science and Embase. No filters were applied to these initial search strategies. Final searches on these databases were carried out on November $6^{\text {th }}$, 2018. The three searches were combined and duplicates removed. Additionally, a hand-searching was performed by checking the reference lists of obtained articles and an automatic search alert feed on PubMed and WoS notified whether new articles were published based on our search strategy, up to October 21, 2019. An overview of MeSH terms, keywords and final search strategies can be found in Appendix 1 (Table S1.)

\section{Study selection}

The screening team consisted out of four researchers and was divided into two groups of two people, with two researchers that screened first half of the articles and the second group evaluating the other part. A first screening was executed on title and abstract and a second screening on full-text. When screening was finished, a meeting was organized to discuss the results whereat any disagreements were resolved by oral discussion and consensus.

\section{Methodological quality assessment of individual studies}

To evaluate the risk of bias in selected studies, the Newcastle-Ottawa Scale for observational studies was used (Table 1) ${ }^{36}$. All articles - both cohort and cross-sectional studies - were scored with the subscale for cohorts. This 8-item checklist is subdivided into three domains: selection, comparability and outcome. Two researchers (S.H., K.V.W.) independently completed the checklist and subsequently discussed their results. Next, a level of evidence was assigned to each study following the EBRO (Evidence-Based Guideline Development) method ${ }^{37}$. Each study was graded a level of evidence ranging from $D$ up to $A 1$, depending on EBM domain, study design and individual methodological quality. Consequently, the strength of conclusion (level 1-4) was assigned to the different outcome levels, taking into account the composition of the respective levels of evidence and consistency of their results ${ }^{37}$.

\section{Data items and extraction}

Two researchers (S.H., K.V.W.) individually read the included articles and extracted data using a pre-determined data extraction form. Differences in data forms were resolved by consensus and all relevant information from the included studies was gathered and consistently summarized in the evidence table. The following data were extracted: (1) year of publication, (2) study design and - if present - follow-up period, (3) population characteristics, (4) parameters of GV, (5) outcome measures of cardiovascular autonomic function and (6) results for each outcome. 


\section{RESULTS}

\section{Study selection}

The overview with the number of hits for each database search is shown in Supplementary Table S2. The combination of the three search strategies yielded 2574 hits and the hand-searching resulted in 2 additional studies. This was reduced to 2054 articles after removing duplicates. After the first screening, only 27 articles remained. The second screening resulted in a final number of 6 articles to be included. (Figure 1. Flowchart study selection)

\section{Study characteristics}

This review contains six eligible studies, of which four cross-sectiona| ${ }^{38-41}$ and two prospective cohort studies with a follow-up of 3 and 10 years ${ }^{42,43}$. The sample size of the cross-sectional studies varied between 20-80 patients and the cohort studies included respectively 41 and 1375 patients ${ }^{42,43}$. All six studies included adults, with a mean age range between $27-47$ years. Mean HbA1c values were similar between different study populations, within a range of $64-75 \mathrm{mmol} / \mathrm{mol}(8-9 \%)$ and mean time since diagnosis varied from 2.6 to 17.5 years. Considering the methods for determination of GV, five studies used CGM ${ }^{38-42}$ for a duration between 1-6 days, while one study used 7-point capillary blood glucose profiles at 3 months intervals ${ }^{43}$. SD and MAGE of glucose values were the most studied parameters of GV, determined in five studies ${ }^{38,40-43}$. Hypoglycaemic indices (LBGI, AUC hypo and \%time in hypo) were reported in three studies ${ }^{39,40,42}$. COV glucose and M-value (two studies); CONGA, MODD and MAG (one study) were used less frequently. All studies used CARTS or HRV to assess cardiac autonomic function, except one that examined blood pressure dipping ${ }^{42}$. Three studies also determined whether or not CAN was present, all of them basing CAN diagnosis on the results of CARTs ${ }^{40,41,43}$.

\section{Risk of bias within studies}

Since it is impossible for T1DM patients not to demonstrate GV as it is omnipresent in this population, the 'nonexposed cohort'-criteria were not assessed, i.e. it was not applicable to score questions 2 and 5 of the NOS scale ('Selection of non-exposed cohort' and 'Comparability of cohorts', respectively). Question 3 (Ascertainment of exposure) was scored positive for all studies that used CGM since a complete glucose data profile is obtained wrich objectively reflects GV. The most common positive scored question was 'Ascertainment of exposure' (five studies) and 'Assessment of outcome' (all studies). One included publication obtained level of evidence A2 ${ }^{43}$, one study level $B{ }^{42}$ because of lacking the required $A 2$ criteria ${ }^{37}$ and a level $C$ was granted to all four cross-sectional studies since these were non-comparative ${ }^{38-41}$. Results of risk of bias assessment are shown in Table 1. Consequently, a level of conclusion 3 was assigned to the two outcomes, HRV and CARTs (Synthesis of results).

\section{Summary of individual study results}

An overview of all individual studies is shown in Table 2 and their key findings are presented in Table 3.

\section{Synthesis of results: Relationship between GV and cardiovascular autonomic function in T1DM}


Association between GV and HRV parameters. Two studies examined the relationship between short-term GV (both based on CGM) and HRV and both found significant negative associations ${ }^{38,39}$. Significant negative associations between higher hypoglycaemic indices and LF power as a frequency-domain measure of HRV (LBGILF power: $R^{2}=0.351$; AUC hypo-LF power: $R^{2}=0.316$ ), were reported in a population without evidence of diabetic complications ${ }^{39}$. Other research found significant negative correlations between COV-RR (time-domain HRV) and intraday GV parameters ( $r=$ from -0.38 to -0.65 ), which was especially pronounced during night-time ${ }^{38}$. Thus, high short-term GV might negatively affect HRV (level of conclusion 3).

Association between GV and CART parameters. Four studies evaluated CART parameters, as determinants of cardiovascular autonomic function or to assess whether or not CAN was present ${ }^{39-41,43}$, but showed ambiguous results (level of conclusion 3). One study did not find significant associations between hypoglycaemic indices and CART-ratios ${ }^{39}$, and the prospective cohort study based on data from the DCCT found no significant association between within-day GV (from 7-point capillary blood glucose) and the risk for CAN after adjusting for MBG ${ }^{43}$. Two more recently published studies (2018) both reported significant associations between GV and CAN, however, they did not completely confirm each other as they used different covariates in statistical analysis. The study of Njiraty et al. found a tendency of higher GV in the CAN group ( $n=10 / 20$ ), as well as significant positive correlations between two GV parameters (SD, MAG) and CAN-scores (based on CARTs; $r=$ from 0.47 to 0.62 ), but only one remained significant (SD glucose $-\mathrm{SBP}$ fall; $r=0.49$ ) after adjusting for $\mathrm{HbA1c}$, age and disease duration ${ }^{41}$. On the other hand, the study of Jun et al. in 80 patients found that several parameters of GV (SD, COV, MAGE, LBGI, $\mathrm{HBGl}$, \%-time in hypoglycaemia and AUC hypo) were independently associated with CAN, all of this after adjusting for MBG and clinical risk factors. Level 2 hypoglycaemia $(<54 \mathrm{mg} / \mathrm{dl}$ ) showed the highest relative contribution to this association in this study (standardized weight $=0.4135 ; p=0.001)^{40}$. 


\section{DISCUSSION}

\section{Statement of principal findings: summary of evidence}

This systematic review examined the association between GV - a concept increasingly gaining attention - and CAN, a clinical expression of cardiovascular autonomic dysfunction and an underestimated problem in T1DM. The scarcity of data (only 6 studies), together with the null finding from prospective studies, makes it hard to draw solid conclusions and points to an urgent need for more research into this relationship. Concerning the impact of GV on HRV, as a measure of CAN, high short-term GV might negatively affect parameters of HRV as shown by two cross-sectional studies (level of conclusion 3) ${ }^{38,39}$. Regarding the association between GV and the results of CARTs as determinants of cardiovascular autonomic function, ambiguous results were reported by included studies ${ }^{40-43}$. While two studies did not find significant associations between GV indices and CART-parameters after adjusting for mean blood glucose $(M B G)^{39,43}$, two more recent studies however, did found significance ${ }^{40,41}$. Hence, uncertainty remains about the impact of GV on cardiovascular autonomic reflex function (level of conclusion 3 ).

\section{Methodological considerations of GV and CAN assessment - Strengths and weaknesses of included studies}

Heterogeneity in methodological approach - both for GV and CAN assessment - makes it difficult to fully compare the different study results and therefore hard to draw solid conclusions about their relationship.

Cardiovascular autonomic function. Regarding HRV, assessment should take place under well-standardised conditions as recommended by the Task Force on HRV ${ }^{44}$. Spectral analysis of RR-intervals (for determination of frequency-domain HRV) is most valid and reliable if monitored under resting conditions (concept of stationarity), preferably after ten minutes of supine rest in a darkened room and abstained from nicotine, caffeine or pharmacologic agents that interfere with HR or blood pressure ${ }^{44}$. Once again, this is often not reported in studies. HRV assessment should comprise both time- and frequency-domain measures. This was not the case in two studies, with the evaluation of only time- or frequency-domain HRV, respectively ${ }^{38,39}$. From the existing multiplicity of time-domain measures, the Task Force recommends four of them (SDNN, SDANN, HRV triangular index and RMSSD) ${ }^{44}$. Furthermore, it is not useful to compare time-domain measures obtained from recordings of unferent durations. Duration should be standardized and a short-term five-minute resting evaluation or an entire 24h-recording are both useful44,45. Also for CARTs, studies should strictly follow recommendations on how to perform and interpret these tests since several confounding factors have been identified ${ }^{46,47}$.

CAN diagnosis: clear cut case or tricky business? Next to the heterogeneity in HRV analysis and CART evaluation, the diagnosis of CAN is not unambiguous as well ${ }^{47}$. Moreover, this differed between included studies as other criteria were used for CAN diagnosis. All studies based CAN diagnosis on the results of CARTs, however with different interpretations of these tests ${ }^{40,41,43}$. Although different criteria for CAN are found in literature, studies should adhere to one clear algorithm ${ }^{47}$. CARTs, if executed correctly, are considered the gold-standard in CAN diagnosis since they are safe, non-invasive and can be well-standardized ${ }^{23,24}$. The traditional classification in 
early, confirmed and severe CAN remains useful ${ }^{47-49}$ but an 'autonomic neuropathy score' - obtained by scoring the results of CARTs - is advised because of its dual advantage of evaluating the progression of CAN and providing an overall quantitative result ${ }^{46}$. Secondly, HRV monitoring is a valuable tool for assessing cardiovascular autonomic function, with some researchers even claiming that it is the most sensitive and specific method ${ }^{50,51}$. HRV could detect early changes in myocardial autonomic innervation and thus CAN in sub-clinical stages ${ }^{23,52,53}$, even in young patients ${ }^{54}$. In our opinion, both HRV analysis and CARTs should be performed in order to have extensive insight into patients' cardiovascular autonomic function and potential CAN diagnosis ${ }^{23,24,47}$. Moreover, by evaluating both HRV and CARTs, the cardiovascular branches of the ANS are examined at rest as well as under stress conditions, as resting HRV reflects the sympathetic and parasympathetic HR modulation while the CARTs mainly evaluate the capacity of the cardiovascular reflexes to react on stimuli. Moreover, assessment of cardiovascular autonomic function can also comprise other aspects, such as evaluation of baroreflex function measured by baroreflex sensitivity (BRS). As BRS was found to be reduced in T1DM ${ }^{55-57}$ and able to differentiate patients with CAN from those without ${ }^{58}$, it could be a valuable adjunct in reflecting cardiovascular autonomic function ${ }^{58,59}$. BRS can be estimated non-invasively through analysis of spontaneous beat-to-beat fluctuations of BP and R-R interval lengths on ECG59.

Non-dipping blood pressure: phenomenon needing attention. The clinical importance of this aberrant BP pattern is well-known since non-dippers showed a higher incidence of cardiovascular events and target organ damage ${ }^{60,61}$. There is still uncertainty about the exact pathogenesis of this loss of normal nocturnal BP decrease. Hypertension, renal function impairment and altered nocturnal sympathovagal balance are often linked to the aetiology of non-dipping ${ }^{61,62}$ and non-dipping is sometimes considered as a surrogate measure of CAN ${ }^{63-66}$. Concerning the role of GV, higher postprandial BG excursions were found to be related to non-dipping in T2DM, with both endothelial and autonomic nervous dysfunction (sympathetic overdrive) proposed as potential mechanistic linkages ${ }^{64}$. In this review, only one study examined the association between non-dipping and GV but did not found significance, not at baseline nor after follow-up ${ }^{42}$. However, this was only for three years, which might have been too short to detect any significant association. Still, the authors stated that GV can act as a putential risk factor driving non-dipping, which may lead to silent $\mathrm{CVD}^{42}$. In the future, mechanisms of nondipping, as well as the associations between abnormal diurnal variation in BP and blood glucose, need further research.

Assessment of glycaemic variability. Only CGM provides a full picture of short-term glucose fluctuations and consequently captures the full degree of GV, as CGM-outputs comprise 5-min interval glucose values from which all existing parameters can be calculated ${ }^{67,68}$. The 7-point capillary BG profile on the other hand, used in the study of Lachin et al. with data from the $\mathrm{DCCT}^{43}$, is insufficient to characterize GV correctly, as the validity of this method is strongly dependent on the timing and number of finger prick measurements throughout the day and often many data points are missing ${ }^{69-71}$. However, multiple imputation methods were used in the study of Lachin 
et al., making their results somewhat more reliable ${ }^{43}$. Regarding the use of CGM in research, the system should be used for at least seven days ${ }^{68}$, which conflicts with two studies that only implemented CGM for two and three days, respectively ${ }^{38,40}$. Besides this, to get a reliable picture of the everyday GV of a patient, standardised instructions are needed. Patients should retain their normal activities of daily living including usual eating habits and physical activity level, which is often not specified in the methodology section of included studies.

The plethora of existing GV parameters: bless or burden? Many different parameters were used in the included studies to reflect GV, but one should be cautious when interpreting or comparing results of studies since not all indices are equivalent as they can represent different concepts ${ }^{72}$. Some of these parameters are highly correlated and actually comprise the same information, while others do not ${ }^{73}$. A combination of the most relevant indices is necessary to effectively describe GV. For example, COV is more valid than SD in reflecting overall GV ${ }^{74}$ and more sensitive in predicting hypoglycaemia ${ }^{9,74}$, while the MAGE index mainly reflects mealtime-related GV7. The importance of avoiding excessive post-meal glucose excursions is evidently acknowledged since this substantially contributes to hyperglycaemic exposure and thus $\mathrm{MBG}^{75}$. Therefore, the advantage of MAGE is that it only assesses major glucose swings and excludes minor ones, being considered as a measure of unstable diabetes ${ }^{76}$. Also between-day GV - assessed by the MODD - needs further investigation. In this review, however, only one study reported this parameter ${ }^{38}$. In conclusion, future studies should focus on standardizing the methods for GV assessment and its two most important components: amplitude and timing 68,77 . A uniform set of GV parameters is needed and studies should separately report the results per parameter. Fabris et al. showed that more than 25 parameters could be reduced to a set of 10, comprising all necessary information on GV ${ }^{78}$. More studies are needed to examine which of these GV parameters offer advantage in predicting diabetic complications $^{72}$. Importantly however, most of aforementioned parameters (SD, MAGE, MODD) are still dependent on mean glycaemia. Simply adjusting for MBG might not be enough to exclude the possibility that the observed association actually comes from the difference in MBG. COV and MAG at the contrary are not dependent on $M B G$ and have been recommended by DeVries et al. to reflect true glucose variability ${ }^{79}$. Taking this into consideration and looking closer at included studies, we evaluated the impact of excluding the meanuependent CGM-parameters. Iwasaki et al. ${ }^{38}$ assessed only mean-dependent parameters (SD, MAGE, M-value, MODD), which makes this small cross-sectional study somewhat less robust. Also for the study of Njiraty et al. ${ }^{41}$, uncertainty increased if we exclude SD glucose as parameter for GV, as this was the only remaining significant correlation in the multiple regression model. On the other hand, interpretation of the study results of Jun et al. ${ }^{40}$ (assessing SD, MAGE and COV) did not change, as COV was significantly associated with CAN risk in all regression models.

Hypoglycaemia as underlying disturbing factor. Lowering patient's MBG is only possible if GV is constrained, otherwise BG fluctuations would inevitably enter the range of hypoglycaemia ${ }^{80}$. Increased hypoglycaemia due to excess GV has been demonstrated in several studies, showing GV to be a predictor of hypoglycaemic events ${ }^{78,81,82}$. 
Therefore, it is interesting to explore whether the increased hypoglycaemia is more important than GV itself and whether it is independently associated with the outcomes of interest. Hypoglycaemia was found to be associated with lengthening of the QTc interval on ECG ${ }^{83,84}$ and reduction of cardiac vagal outflow with diminished HRV $85-87$. Hence, the impact of hypoglycaemia on cardiac autonomic regulation should not be neglected ${ }^{88}$. In this review, two studies evaluated parameters describing hypoglycaemia and both found significant results ${ }^{39,40}$. However, several parameters can characterise hypoglycaemia: area under the curve (AUC hypo), \%-time spent in hypoglycaemia, number of hypoglycaemic events or the LBGI (risk index). The study of Jun et al. found significant results for all of these hypoglycaemic parameters ${ }^{40}$. Once again, these indices are not equivalent as they reflect different aspects. The AUC hypo gives complete insight into the severity of hypoglycaemia since there is a contribution from both time of exposure and level of hypoglycaemia; while time spent in hypoglycaemia (\%) only reflects total duration but not severity. Separate monitoring of time in level 2 hypoglycaemia $(<54 \mathrm{mg} / \mathrm{dl})$ showed the highest contribution to the reported associations and can provide a solution for this issue ${ }^{40}$. Hence, future studies should further elucidate the importance of (level 2) hypoglycaemia, next to parameters of GV.

Covariates in the relationship between GV and CAN . Lastly, as with many studies, study populations were rather heterogeneous: from adolescents ${ }^{89}$ to complication-free patients ${ }^{39,40,42}$ and patients with established complication status ${ }^{38,41}$. The question remains if results can be generalised for the entire patient spectrum since the effects of GV could vary throughout the broad range of disease duration and complication status. These aspects should be as much as possibly adjusted for in statistical analysis but varied widely between included studies. While Jun et al. used age, $\mathrm{HbA1c}$ and disease duration as covariates ${ }^{40}$, the study of Njiraty et al. adjusted for smoking, BMI and $\mathrm{SBP}^{41}$ and Virk et al. also adjusted for body height and socio-economic status ${ }^{89}$. Future studies should uniformly adjust only for the known risk factors of CAN (as pointed out previously in the introduction of this review) as covariates in their analyses and thereby decrease the risk for overfitting.

\section{Role of GV in diabetic complications: time to shed clarity on this unanswered question?}

Regarding the underlying pathophysiology, the frequent occurrence of both excessive glucose decrements and increments increases the amount of oxidative stress and inflammatory markers, which was reported to be the

key mediator in the detrimental effect on vascular and nerve function ${ }^{8,18,90-94}$. While some in vitro studies found that acute glycaemic swings can induce endothelial cell damage via excessive formation of free oxygen radicals ${ }^{95}$, in vivo research did not confirm this association between high GV and increased oxidative stress (by urinary excretion rates of 8-iso-PGF2 $\alpha$ ) in T1DM patients ${ }^{96}$. The term Pyramid of the Risk was introduced after the finding that GV - next to the classic glucose triad of mean, fasting and postprandial BG - may also have deleterious effects on the development of diabetic complications ${ }^{97}$. Previous reviews concluded that GV has if any, only minimal impact on the development of diabetic complications, however, most of the studies in these reviews reanalysed data from the DCCT in which GV was determined using 7-point capillary BG profiles and not CGM ${ }^{15,16}$. A recent review from The Lancet concluded that it has not yet been definitively confirmed whether GV is an 
independent risk factor for diabetes complications ${ }^{6}$. Concerning the relationship of GV with CAN in T1DM in particular, only a few studies focused on this association, all of them included in this review.

Causality and importance of the relationship between GV and cardiovascular autonomic dysfunction. The cross-sectional nature of many studies prevents inferring a causal relationship. Furthermore, one can also question the direction of this possible association, i.e. 'what is cause and consequence and vice versa?'. While GV may negatively impact sympathovagal balance by increasing oxidative stress as mentioned before ${ }^{22,98}$, autonomic dysfunction on the other hand may reciprocally affect GV due to disturbed glucose counter-regulation and decreased hypoglycaemic awareness ${ }^{88,99}$. These latter two are often present in long-standing T1DM and may result in even more pronounced fluctuations and hypoglycaemic events ${ }^{100,101}$. In summary, the direction of the association remains to be elucidated, but is perhaps bidirectional as it is not clear whether autonomic dysfunction drives GV or the other way around.

\section{Strengths and limitations of this review}

This systematic review comprises a comprehensive literature search up to 2019 with extensive search strategies on three major databases. The methodological quality of included studies was carefully and critically assessed with levels of evidence based on the risk of bias. Finally, we present a thorough discussion of important methodological considerations as well as implications for further research. Potential limitations of this review could include the limited amount of studies - with four cross-sectional and two prospective studies - and inclusion of only articles written in English, French or Dutch.

\section{CONCLUSION}

This systematic review found some preliminary evidence supporting the hypothesis of an association between GV and cardiovascular autonomic dysfunction in T1DM. The scarcity of data (only 6 studies), together with the null finding from prospective studies, makes it hard to draw solid conclusions and points to an urgent need for more research into this relationship. At this moment, uncertainty remains whether high GV can independently itribute to the onset or progression of CAN. The heterogeneity in methodological approach makes it difficult to compare different studies. Future studies should therefore use uniformly evaluated CGM-derived parameters of GV, while standardised assessment of HRV, CARTs and other potential cardiac autonomic function parameters is needed for an unambiguous definition of CAN.

Acknowledgments. We would like to thank M. Meeus (PhD; Ghent University; Antwerp University; University of Brussels (VUB), Belgium) who helped with the selection and scoring of the appropriate checklist for the methodological quality assessment, as well as with the structure of this review by using her book 'Health literacy: from reference to review'. 
Funding. The primary author (S. Helleputte) is supported by a PhD grant of the Special Research Fund of Ghent University (BOF grant) at the Department of Rehabilitation Sciences, Faculty of Medicine, Ghent University, Belgium. There was no external financial support for this review, neither specific grants from any funding agency in the public, commercial or non-profit sectors.

Conflict of Interest. None of the authors had any personal or financial conflict of interest associated with this manuscript.

Author Contributions. The following people collaborated on this systematic review, with their respective contributions: S.H. (original idea for the review, search strategies, screening, methodological quality assessment, data review and interpretation, writing), P.C. (screening, data interpretation, methodological quality assessment, writing and revision of manuscript), K.V.W. (protocol, screening, methodological quality assessment, revision of manuscript), B. Celie (writing and revision of manuscript), B.V.E. (protocol, screening, methodological quality assessment), T.D.B. (data interpretation, writing and revision of manuscript), B.L. (writing and revision of manuscript) and S.S. (revision of manuscript). All authors provided input throughout the entire review protocol, read and approved the final manuscript and identify the primary author (S.H.) as the person having full responsibility of this systematic review.

\section{REFERENCES}

1. Nathan DM, Genuth S, Lachin J, et al. The effect of intensive treatment of diabetes on the development and progression of long-term complications in insulin-dependent diabetes mellitus. $N$ Engl J Med. 1993;329(14):977-986.

6. Glycemic Targets: Standards of Medical Care in Diabetes-2019. Diabetes Care. 2019;42(Suppl 1):S61-s70.

Suh S, Kim JH. Glycemic Variability: How Do We Measure It and Why Is It Important? Diabetes \& Metabolism Journal. 2015;39(4):273-282.

Hirsch IB. Glycemic Variability and Diabetes Complications: Does It Matter? Of Course It Does! Diabetes Care. 2015;38(8):1610-1614.

5. Hirsch IB, Brownlee M. Should minimal blood glucose variability become the gold standard of glycemic control? Journal of Diabetes and Its Complications. 2005;19(3):178-181.

6. Ceriello A, Monnier L, Owens D. Glycaemic variability in diabetes: clinical and therapeutic implications. Lancet Diabetes \& Endocrinology. 2019;7(3):221-230.

Rodbard D. Interpretation of Continuous Glucose Monitoring Data: Glycemic Variability and Quality of Glycemic Control (vol 11, pg S-55, 2009). Diabetes Technology \& Therapeutics. 2018;20(4):320-320.

8. Monnier L, Colette C, Owens D. Glycemic Variability: The Third Component of the Dysglycemia in Diabetes. Is It Important? How to Measure It? Journal of diabetes science and technology. 2008;2(6):1094-1100.

9. Rama Chandran S, Tay WL, Lye WK, et al. Beyond HbA1c: Comparing Glycemic Variability and Glycemic Indices in Predicting Hypoglycemia in Type 1 and Type 2 Diabetes. Diabetes Technology \& Therapeutics. 2018;20(5):353-362.

10. Kohnert KD, Heinke P, Fritzsche G, Vogt L, Augstein P, Salzsieder E. Evaluation of the Mean Absolute Glucose Change as a Measure of Glycemic Variability Using Continuous Glucose Monitoring Data. Diabetes Technology \& Therapeutics. 2013;15(6):448-454.

11. Kohnert KD, Heinke P, Vogt L, Salzsieder E. Utility of different glycemic control metrics for optimizing management of diabetes. World Journal of Diabetes. 2015;6(1):17-29.

12. Kovatchev BP, Otto E, Cox D, Gonder-Frederick L, Clarke W. Evaluation of a new measure of blood glucose variability in diabetes. Diabetes Care. 2006;29(11):2433-2438. 
13. Monaghan M, Cogen FR, Streisand R. Average Daily Risk Range (ADRR) in Young Children With Type 1 Diabetes. Journal of diabetes science and technology. 2014;8(1):70-73.

14. Patton SR, Clements MA. Average daily risk range as a measure for clinical research and routine care. Journal of diabetes science and technology. 2013;7(5):1370-1375.

15. Nalysnyk L, Hernandez-Medina M, Krishnarajah G. Glycaemic variability and complications in patients with diabetes mellitus: evidence from a systematic review of the literature. Diabetes Obesity \& Metabolism. 2010;12(4):288-298.

16. Smith-Palmer J, Brandle M, Trevisan R, Federici MO, Liabat S, Valentine W. Assessment of the association between glycemic variability and diabetes-related complications in type 1 and type 2 diabetes. Diabetes Research and Clinical Practice. 2014;105(3):273-284.

17. Kilpatrick ES, Rigby AS, Atkin SL. Effect of glucose variability on the long-term risk of microvascular complications in type 1 diabetes. Diabetes Care. 2009;32(10):1901-1903.

18. Brownlee M, Hirsch I. Glycemic Variability: A Hemoglobin A1c- Independent Risk Factor for Diabetic Complications. Jama Internal Medicine. 2006;295(14).

19. Soupal J, Skrha J, Jr., Fajmon M, et al. Glycemic variability is higher in type 1 diabetes patients with microvascular complications irrespective of glycemic control. Diabetes technology \& therapeutics. 2014;16(4):198-203.

20. Bragd J, Adamson U, Backlund LB, Lins PE, Moberg E, Oskarsson P. Can glycaemic variability, as calculated from blood glucose self-monitoring, predict the development of complications in type 1 diabetes over a decade? Diabetes Metab. 2008;34(6 Pt 1):612-616.

21. Sartore G, Chilelli NC, Burlina S, Lapolla A. Association between glucose variability as assessed by continuous glucose monitoring (CGM) and diabetic retinopathy in type 1 and type 2 diabetes. Acta diabetologica. 2013;50(3):437-442.

22. Spallone V, Kempler P, Czupryniak L, et al. The Interplay between Dysglycaemia and Autonomic Function. Diabetes Stoffwechsel Und Herz. 2018;27(3):135-144.

23.

Fisher VL, Tahrani A. Cardiac autonomic neuropathy in patients with diabetes mellitus: current perspectives. Diabetes Metabolic Syndrome and Obesity-Targets and Therapy. 2017;10:419-434.

24. Serhiyenko VA, Serhiyenko AA. Cardiac autonomic neuropathy: Risk factors, diagnosis and treatment. World journal of diabetes. 2018;9(1):1-24.

25. Dafaalla MD, Nimir MN, Mohammed MI, Ali OA, Hussein A. Risk factors of diabetic cardiac autonomic neuropathy in patients with type 1 diabetes mellitus: a meta-analysis. Open Heart. 2016;3(2).

26. Kario K. Nondipping in nocturnal blood pressure in diabetes: An indicator of autonomic nervous dysfunction? American Journal of Hypertension. 2007;20(5):546-547.

27. Spallone V, Ziegler D, Freeman R, et al. Cardiovascular autonomic neuropathy in diabetes: clinical impact, assessment, diagnosis, and management. Diabetes-Metabolism Research and Reviews. 2011;27(7):639-653.

28. Kempler P, Tesfaye S, Chaturvedi N, et al. Autonomic neuropathy is associated with increased cardiovascular risk factors: the EURODIAB IDDM Complications Study. Diabetic Medicine. 2002;19(11):900-909.

Maser RE, Mitchell BD, Vinik Al, Freeman R. The association between cardiovascular autonomic neuropathy and mortality in individuals with diabetes - A meta-analysis. Diabetes Care. 2003;26(6):1895-1901.

30. Spallone V, Bellavere F, Scionti L, et al. Recommendations for the use of cardiovascular tests in diagnosing diabetic autonomic neuropathy. Nutrition Metabolism and Cardiovascular Diseases. 2011;21(1):69-78.

31. Fleischer J, Cichosz SL, Hoeyem P, et al. Glycemic Variability Is Associated With Reduced Cardiac Autonomic Modulation in Women With Type 2 Diabetes. Diabetes Care. 2015;38(4):682-688.

32. Jun JE, Jin SM, Baek J, et al. The association between glycemic variability and diabetic cardiovascular autonomic neuropathy in patients with type 2 diabetes. Cardiovascular Diabetology. 2015;14.

33. Matsutani D, Sakamoto M, luchi H, et al. Glycemic variability in continuous glucose monitoring is inversely associated with baroreflex sensitivity in type 2 diabetes: a preliminary report. Cardiovascular Diabetology. $2018 ; 17$.

34.

Xu W, Zhu YH, Yang XB, et al. Glycemic variability is an important risk factor for cardiovascular autonomic neuropathy in newly diagnosed type 2 diabetic patients. International Journal of Cardiology. 2016;215:263268. 
35. Liberati A, Altman DG, Tetzlaff J, et al. The PRISMA Statement for Reporting Systematic Reviews and MetaAnalyses of Studies That Evaluate Health Care Interventions: Explanation and Elaboration. Plos Medicine. 2009;6(7):28.

36. Newcastle Ottawa Scale (NOS) for assessing methodological quality of observational studies. 2019; http://www.ohri.ca/programs/clinical_epidemiology/nosgen.pdf. Accessed January 17, 2019, 2019.

37. Meeus M. GN. Health Literacy: From reference to review. P164-166; Leuven/Den Haag: Acco; 2016.

38. Iwasaki S, Kozawa J, Fukui K, Iwahashi H, Imagawa A, Shimomura I. Coefficient of variation of R-R interval closely correlates with glycemic variability assessed by continuous glucose monitoring in insulin-depleted patients with type 1 diabetes. Diabetes Research and Clinical Practice. 2015;109(2):397-403.

39. Jaiswal M, McKeon K, Comment N, et al. Association Between Impaired Cardiovascular Autonomic Function and Hypoglycemia in Patients With Type 1 Diabetes. Diabetes Care. 2014;37(9):2616-2621.

40. Jun JE, Lee SE, Lee YB, et al. Continuous glucose monitoring defined glucose variability is associated with cardiovascular autonomic neuropathy in type 1 diabetes. Diabetes/metabolism research and reviews. 2018;e3092.

41. Nyiraty S, Pesei F, Orosz A, et al. Cardiovascular Autonomic Neuropathy and Glucose Variability in Patients With Type 1 Diabetes: Is There an Association? Frontiers in Endocrinology. 2018;9(174).

42. Jaiswal M, Ang L, Mizokami-Stout K, Pop-Busui R. Is there an association between non-dipping blood pressure and measures of glucose variability in type 1 diabetes? Journal of Diabetes and Its Complications. 2018;32(10):947-950.

43. Lachin JM, Bebu I, Bergenstal RM, et al. Association of Glycemic Variability in Type 1 Diabetes With Progression of Microvascular Outcomes in the Diabetes Control and Complications Trial. Diabetes Care. 2017;40(6):777783.

Heart rate variability. Standards of measurement, physiological interpretation, and clinical use. Task Force of the European Society of Cardiology and the North American Society of Pacing and Electrophysiology. Eur Heart J. 1996;17(3):354-381.

45. Migliaro ER, Contreras P. Heart rate variability: short-term studies are as useful as holter to differentiate diabetic patients from healthy subjects. Ann Noninvasive Electrocardiol. 2003;8(4):313-320.

46. Spallone V, Bellavere F, Scionti L, et al. Recommendations for the use of cardiovascular tests in diagnosing diabetic autonomic neuropathy. Nutrition, metabolism, and cardiovascular diseases : NMCD. 2011;21(1):69-78. Spallone V, Ziegler D, Freeman R, et al. Cardiovascular autonomic neuropathy in diabetes: clinical impact, assessment, diagnosis, and management. Diabetes/metabolism research and reviews. 2011;27(7):639-653. Diagnosis and management of diabetic autonomic neuropathy. Br Med J (Clin Res Ed). 1982;285(6351):1353. Vinik Al, Mehrabyan A. Diagnosis and management of diabetic autonomic neuropathy. Comprehensive therapy. 2003;29(2-3):130-145.

50. Li K, Rudiger H, Ziemssen T. Spectral Analysis of Heart Rate Variability: Time Window Matters. Front Neurol. 2019;10:545.

Rolim LC, de Souza JS, Dib SA. Tests for early diagnosis of cardiovascular autonomic neuropathy: critical analysis and relevance. Frontiers in endocrinology. 2013;4:173.

52. Nunan D, Sandercock GR, Brodie DA. A quantitative systematic review of normal values for short-term heart rate variability in healthy adults. Pacing Clin Electrophysiol. 2010;33(11):1407-1417.

53. Turker $Y$, Aslantas $Y$, Aydin $Y$, et al. Heart rate variability and heart rate recovery in patients with type 1 diabetes mellitus. Acta cardiologica. 2013;68(2):145-150.

Razanskaite-Virbickiene D, Danyte E, Mockeviciene G, Dobrovolskiene R, Verkauskiene R, Zalinkevicius R. Can coefficient of variation of time-domain analysis be valuable for detecting cardiovascular autonomic neuropathy in young patients with type 1 diabetes: a case control study. BMC cardiovascular disorders. 2017;17(1):34. Dalla Pozza R, Bechtold S, Bonfig W, et al. Impaired short-term blood pressure regulation and autonomic dysbalance in children with type 1 diabetes mellitus. Diabetologia. 2007;50(12):2417-2423. Krause M, Rudiger H, Bald M, Nake A, Paditz E. Autonomic blood pressure control in children and adolescents with type 1 diabetes mellitus. Pediatric diabetes. 2009;10(4):255-263. 
57. Svacinova J, Honzikova N, Krticka A, Tonhajzerova I, Javorka K, Javorka M. Diagnostic significance of a mild decrease of baroreflex sensitivity with respect to heart rate in type 1 diabetes mellitus. Physiological research. 2013;62(6):605-613.

58. Kaminska A, Tafil-Klawe M, Smietanowski M, et al. Spontaneous baroreflex sensitivity in subjects with type 1 diabetes with and without cardiovascular autonomic neuropathy. Endokrynologia Polska. 2008;59(5):398-402.

59. Westerhof BE, Gisolf J, Stok WJ, Wesseling KH, Karemaker JM. Time-domain cross-correlation baroreflex sensitivity: performance on the EUROBAVAR data set. Journal of hypertension. 2004;22(7):1371-1380.

60. Fagard $\mathrm{RH}$. Dipping pattern of nocturnal blood pressure in patients with hypertension. Expert review of cardiovascular therapy. 2009;7(6):599-605.

61. Kanbay M, Turgut F, Uyar ME, Akcay A, Covic A. Causes and mechanisms of nondipping hypertension. Clinical and experimental hypertension (New York, NY: 1993). 2008;30(7):585-597.

62. Stella P, Tabak AG, Zgibor JC, Orchard TJ. Late diabetes complications and non-dipping phenomenon in patients with Type 1 diabetes. Diabetes research and clinical practice. 2006;71(1):14-20.

63. Hjortkjaer $\mathrm{HO}$, Jensen $\mathrm{T}$, Kofoed KF, et al. Nocturnal antihypertensive treatment in patients with type 1 diabetes with autonomic neuropathy and non-dipping: a randomised, placebo-controlled, double-blind crossover trial. BMJ open. 2016;6(12):e012307.

64. Kario K. Nondipping in nocturnal blood pressure in diabetes: an indicator of autonomic nervous dysfunction? American journal of hypertension. 2007;20(5):546-547.

65. Spallone V, Gambardella S, Maiello MR, Barini A, Frontoni S, Menzinger G. Relationship between autonomic neuropathy, 24-h blood pressure profile, and nephropathy in normotensive IDDM patients. Diabetes Care. 1994;17(6):578-584.

66. Spallone V, Maiello MR, Cicconetti E, et al. Factors determining the 24-h blood pressure profile in normotensive patients with type 1 and type 2 diabetes. J Hum Hypertens. 2001;15(4):239-246.

Battelino T, Danne T, Bergenstal RM, et al. Clinical Targets for Continuous Glucose Monitoring Data Interpretation: Recommendations From the International Consensus on Time in Range. Diabetes Care. 2019;42(8):1593-1603.

68. Danne $T$, Nimri R, Battelino $T$, et al. International Consensus on Use of Continuous Glucose Monitoring. Diabetes Care. 2017;40(12):1631-1640. Hirsch IB, Brownlee M. The effect of glucose variability on the risk of microvascular complications in type 1 diabetes. Diabetes care. 2007;30(1):186-187; author reply 188-189.

70. Service FJ, O'Brien PC. The effect of glucose variability on the risk of microvascular complications in type 1 diabetes. Diabetes care. 2007;30(1):186; author reply 187-188.

71. Baghurst PA, Rodbard D, Cameron FJ. The minimum frequency of glucose measurements from which glycemic variation can be consistently assessed. Journal of diabetes science and technology. 2010;4(6):1382-1385.

72. Munoz OM, Gomez AM, Maira GJ, Fabian Mauricio LV, Ruiz-Morales AJ. The different methods of assessing glycemic variability, quality of glycemic control and glycemic risk cannot be interpreted as equivalent in clinical practice. Diabetes \& metabolic syndrome. 2018;12(4):555-561.

Rodbard D. The challenges of measuring glycemic variability. Journal of diabetes science and technology. 2012;6(3):712-715.

74. Rodbard D. Clinical interpretation of indices of quality of glycemic control and glycemic variability. Postgraduate medicine. 2011;123(4):107-118.

75. Ketema EB, Kibret KT. Correlation of fasting and postprandial plasma glucose with HbA1c in assessing glycemic control; systematic review and meta-analysis. Arch Public Health. 2015;73:43.

76. Service FJ, Molnar GD, Rosevear JW, Ackerman E, Gatewood LC, Taylor WF. Mean amplitude of glycemic excursions, a measure of diabetic instability. Diabetes. 1970;19(9):644-655.

77. Kovatchev B, Cobelli C. Glucose Variability: Timing, Risk Analysis, and Relationship to Hypoglycemia in Diabetes. Diabetes Care. 2016;39(4):502-510.

78. Fabris C, Facchinetti A, Sparacino G, et al. Glucose variability indices in type 1 diabetes: parsimonious set of indices revealed by sparse principal component analysis. Diabetes technology \& therapeutics. 2014;16(10):644652.

79. DeVries JH. Glucose variability: where it is important and how to measure it. Diabetes. 2013;62(5):1405-1408. 
80. McCall AL, Kovatchev BP. The median is not the only message: a clinician's perspective on mathematical analysis of glycemic variability and modeling in diabetes mellitus. Journal of diabetes science and technology. 2009;3(1):3-11.

81. Monnier L, Colette C, Wojtusciszyn A, et al. Toward Defining the Threshold Between Low and High Glucose Variability in Diabetes. Diabetes care. 2017;40(7):832-838.

82. Rodbard D. Hypo- and hyperglycemia in relation to the mean, standard deviation, coefficient of variation, and nature of the glucose distribution. Diabetes technology \& therapeutics. 2012;14(10):868-876.

83. Marques JL, George E, Peacey SR, et al. Altered ventricular repolarization during hypoglycaemia in patients with diabetes. Diabetic medicine : a journal of the British Diabetic Association. 1997;14(8):648-654.

84. Robinson RT, Harris ND, Ireland RH, Macdonald IA, Heller SR. Changes in cardiac repolarization during clinical episodes of nocturnal hypoglycaemia in adults with Type 1 diabetes. Diabetologia. 2004;47(2):312-315.

85. Koivikko ML, Salmela PI, Airaksinen KE, et al. Effects of sustained insulin-induced hypoglycemia on cardiovascular autonomic regulation in type 1 diabetes. Diabetes. 2005;54(3):744-750.

86. Koivikko ML, Tulppo MP, Kiviniemi AM, et al. Autonomic cardiac regulation during spontaneous nocturnal hypoglycemia in patients with type 1 diabetes. Diabetes care. 2012;35(7):1585-1590.

87. Silva TP, Rolim LC, Sallum Filho C, Zimmermann LM, Malerbi F, Dib SA. Association between severity of hypoglycemia and loss of heart rate variability in patients with type 1 diabetes mellitus. Diabetes/metabolism research and reviews. 2017;33(2).

88. Cryer PE. Hypoglycemia-associated autonomic failure in diabetes. Handb Clin Neurol. 2013;117:295-307.

89. Virk SA, Donaghue KC, Cho YH, et al. Association Between HbA1c Variability and Risk of Microvascular Complications in Adolescents With Type 1 Diabetes. The Journal of clinical endocrinology and metabolism. 2016;101(9):3257-3263.

90. Saisho Y. Glycemic Variability and Oxidative Stress: A Link between Diabetes and Cardiovascular Disease? International Journal of Molecular Sciences. 2014;15(10):18381-18406.

91. Frontoni S, Di Bartolo P, Avogaro A, Bosi E, Paolisso G, Ceriello A. Glucose variability: An emerging target for the treatment of diabetes mellitus. Diabetes research and clinical practice. 2013;102(2):86-95.

92. Herder C, Roden M, Ziegler D. Novel Insights into Sensorimotor and Cardiovascular Autonomic Neuropathy from Recent-Onset Diabetes and Population-Based Cohorts. Trends Endocrinol Metab. 2019;30(5):286-298.

93. Giacco F, Brownlee M. Oxidative stress and diabetic complications. Circ Res. 2010;107(9):1058-1070.

Horvath EM, Benko R, Kiss L, et al. Rapid 'glycaemic swings' induce nitrosative stress, activate poly(ADP-ribose) polymerase and impair endothelial function in a rat model of diabetes mellitus. Diabetologia. 2009;52(5):952961.

95. Maeda M, Hayashi T, Mizuno N, Hattori Y, Kuzuya M. Intermittent High Glucose Implements Stress-Induced Senescence in Human Vascular Endothelial Cells: Role of Superoxide Production by NADPH Oxidase. Plos One. 2015;10(4):14.

96.

Wentholt IME, Kulik W, Michels RPJ, Hoekstra JBL, DeVries JH. Glucose fluctuations and activation of oxidative stress in patients with type 1 diabetes. Diabetologia. 2008;51(1):183-190.

Zaccardi F, Pitocco D, Ghirlanda G. Glycemic risk factors of diabetic vascular complications: the role of glycemic variability. Diabetes-Metabolism Research and Reviews. 2009;25(3):199-207.

98. Fleischer J. Diabetic autonomic imbalance and glycemic variability. Journal of diabetes science and technology. 2012;6(5):1207-1215.

99. Meyer C, Grossmann R, Mitrakou A, et al. Effects of autonomic neuropathy on counterregulation and awareness of hypoglycemia in type 1 diabetic patients. Diabetes Care. 1998;21(11):1960-1966.

100. Cryer PE. Diverse causes of hypoglycemia-associated autonomic failure in diabetes. N Engl J Med. 2004;350(22):2272-2279.

101. Fanelli C, Pampanelli S, Lalli C, et al. Long-term intensive therapy of IDDM patients with clinically overt autonomic neuropathy: effects on hypoglycemia awareness and counterregulation. Diabetes. 1997;46(7):1172-1181. 


\begin{tabular}{|c|c|c|c|c|c|c|c|}
\hline \multirow{2}{*}{ STUDY (DESIGN) } & \multicolumn{6}{|c|}{ CRITERIA } & \multirow{2}{*}{$\begin{array}{l}\text { INDIVIDUAL } \\
\text { STUDY } \\
\text { QUALITY: LEVEL } \\
\text { OF EVIDENCE }\end{array}$} \\
\hline & 1 & 3 & 4 & 6 & 7 & 8 & \\
\hline $\begin{array}{l}\text { Jaiswal et al. (2014) } \\
\text { (cross-sectional) }\end{array}$ & - & + & l & + & / & / & C \\
\hline $\begin{array}{l}\text { Iwasaki et al. (2015) } \\
\text { (cross-sectional) }\end{array}$ & + & + & l & + & / & / & C \\
\hline $\begin{array}{l}\text { Lachin et al. (2017) } \\
\text { (prospective cohort) }\end{array}$ & + & - & + & + & + & + & $A 2$ \\
\hline $\begin{array}{l}\text { Nyiraty et al. (2018) } \\
\text { (cross-sectional) }\end{array}$ & + & + & l & + & l & l & C \\
\hline
\end{tabular}




\begin{tabular}{|c|c|c|c|c|c|c|c|}
\hline $\begin{array}{l}\text { Jaiswal et al. (2018) } \\
\text { (prospective cohort) }\end{array}$ & - & + & $?$ & + & ? & + & $B$ \\
\hline $\begin{array}{l}\text { Jun et al. (2018) } \\
\text { (cross-sectional) }\end{array}$ & + & + & / & + & / & / & C \\
\hline \multicolumn{8}{|c|}{ Newcastle-Ottawa Quality Assessment Scale (NOS) for cohort studies } \\
\hline \multicolumn{8}{|c|}{$\begin{array}{l}\text { Selection of cohort(s): } 1: \text { Representativeness of the exposed cohort; } 3 \text { : Ascertainment of exposure; 4: Demonstration } \\
\text { that outcome was not present at start of the study; }\end{array}$} \\
\hline \multicolumn{8}{|l|}{$\frac{\text { Outcome assessment: }}{\text { follow-up of cohorts }}$} \\
\hline \multicolumn{8}{|c|}{$\begin{array}{l}\text { "+": yes; "-: no; "?": unknown, not mentioned or uncertain; "I": not applicable to score } \\
\text { NOTE: Since it is impossible not to demonstrate glycaemic variability, there was no 'non-exposed cohort' present in the } \\
\text { included studies, making it not applicable to score questions } 2 \text { and } 5 \text { of the NOS scale ('selection of the non-exposed cohort' } \\
\text { and 'comparability of the cohorts', respectively). }\end{array}$} \\
\hline
\end{tabular}

TABLE 1. Risk of bias assessment in individual studies. 


\begin{tabular}{|c|c|c|c|c|c|}
\hline \begin{tabular}{|c|} 
First \\
author \\
(year of \\
publication) \\
\end{tabular} & $\begin{array}{l}\text { Study design } \\
\text { (Follow-up) }\end{array}$ & Population characteristics & $\begin{array}{l}\text { Glycaemic variability: } \\
\text { method of assessment } \\
\text { \& parameters }\end{array}$ & $\begin{array}{l}\text { Cardiovascular autonomic } \\
\text { function: outcomes }\end{array}$ & Results \\
\hline $\begin{array}{c}\text { aiswal et al. }{ }^{39} \\
\text { (2014) }\end{array}$ & $\begin{array}{c}\text { Cross-sectional } \\
\text { analysis baseline } \\
\text { (/) }\end{array}$ & $\begin{array}{l}\mathrm{n}=44 \quad(17 \mathrm{M}, 27 \mathrm{~F}) \\
\text { Age: } 34 \pm 13 \text { yrs (range:18-65) } \\
\text { DD: } 13 \pm 6 \text { yrs (all >5 yrs) } \\
\text { BMI: } 26 \pm 4 \\
\text { HbA1c: } 64 \mathrm{mmol} / \mathrm{mol}(8.0 \pm \\
\text { 1.2\%) } \\
\text { TDI: } 0.7 \pm 0.2 \mathrm{U} / \mathrm{kg} / \text { day }\end{array}$ & $\begin{array}{l}\text { CGM for } 5 \text { days } \\
\text { Indices of hypoglycemic } \\
\text { stress } \\
\begin{array}{ll}\text { - } \quad \text { LBGI } \\
\text { AUC for } \\
\text { hypoglycaemia }(<70 \\
\mathrm{mg} / \mathrm{dl})\end{array}\end{array}$ & $\begin{array}{l}\text { HRV (rest and during CART) } \\
\text { LF power } \\
\text { HF power } \\
\text { CARTs } \\
\text { Deep breathing: E:I-ratio } \\
\text { Valsalva ratio } \\
\text { Standing: } 30: 15 \text { ratio }\end{array}$ & 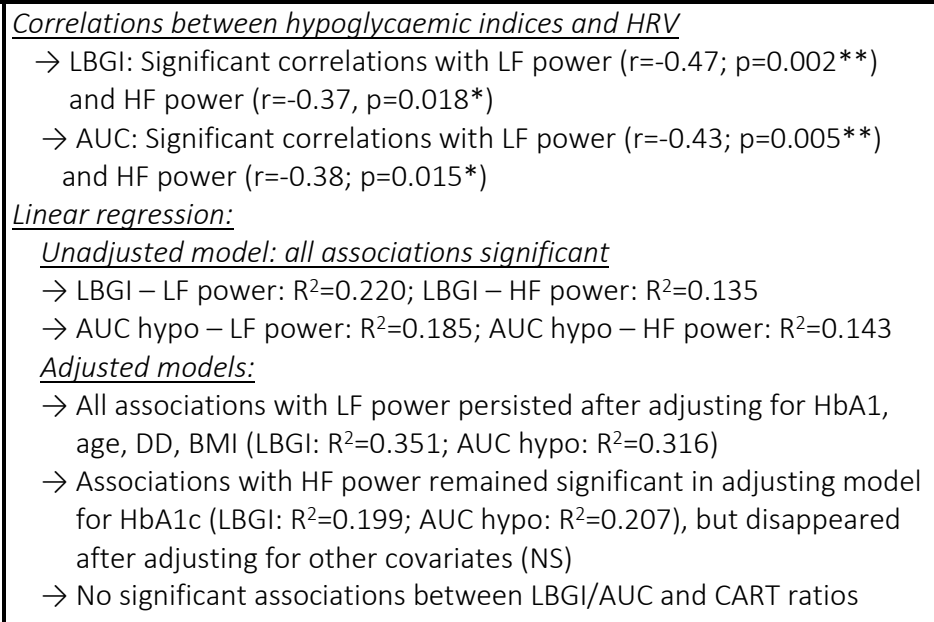 \\
\hline $\begin{array}{c}\text { Iwasaki et } \\
\text { al. }^{38} \\
(2015)\end{array}$ & $\begin{array}{c}\text { Cross-sectional } \\
(/)\end{array}$ & $\begin{array}{l}\mathrm{n}=31 \quad(13 \mathrm{M}, 18 \mathrm{~F}) \\
\text { Hospitalized } \\
\text { Age: } 47.2 \pm 16.4 \mathrm{yrs} \\
\text { DD: } 18.6 \pm 12.8 \mathrm{yrs} \\
\text { BMI: } 22.4 \pm 3.7 \\
\text { HbA1c: } 64 \mathrm{mmol} / \mathrm{mol}(8.0 \pm \\
\text { 1.5\%) } \\
\text { MDI: } \mathrm{n}=20, \mathrm{CSII}: \mathrm{n}=11\end{array}$ & $\begin{array}{l}\text { CGM for }>24 \mathrm{~h}(56.5 \pm \\
15.3 \mathrm{~h}) \\
\text { Intraday GV } \\
\quad \text { SD glucose } \\
\quad \text { MAGE } \\
\frac{\text { Hybrid: MBG \& GV }}{\text { M-value }} \\
\frac{\text { Inter-day GV (2days) }}{\text { MODD }}\end{array}$ & $\frac{\mathrm{HRV}}{\mathrm{COV} \text { of RR-interval }}$ & $\begin{array}{l}\text { Correlations between COV-RR and GV measures } \\
\rightarrow \text { Significant correlations with whole day SD }\left(r=-0.50 ; p=0.007^{* *}\right), \\
\text { MAGE }\left(r=-0.47 ; p=0.011^{*}\right), \text { M-value }\left(r=-0.38 ; p=0.048^{*}\right) \text { and MODD } \\
\left(r=-0.59 ; p=0.001^{* * *}\right) \\
\rightarrow \text { Significant correlations with nighttime SD }\left(r=-0.59, p=0.001^{* * *}\right), \\
\text { MAGE }\left(r=-0.47 ; p=0.011^{*}\right), M-\text { value }\left(r=-0.53 ; p=0.004^{* *}\right) \text { and } \\
\text { MODD }\left(r=-0.65 ; p=0.0003^{* * *}\right) \\
\rightarrow \text { Significant correlations with daytime SD }\left(r=-0.44 ; p=0.019^{*}\right) \text { and } \\
\left.\text { MAGE ( } r=-0.50 ; p=0.006^{* *}\right) ; \text { No significant correlation with daytime } \\
\text { M-value and MODD (NS) }\end{array}$ \\
\hline $\begin{array}{c}\text {-achin et al. }{ }^{43} \\
\text { (2017) }\end{array}$ & $\begin{array}{c}\text { Prospective } \\
\text { cohort }\end{array}$ & $\begin{array}{l}n=1375 \quad(M / F: \text { almost equal }) \\
\text { Age: } 27 \pm 7 y r s\end{array}$ & $\begin{array}{l}\text { 7-point capillary blood } \\
\text { glucose measurement, }\end{array}$ & $\frac{C A N-\text { based on: } C A R T s}{\text { Deep breathing: } \triangle R R \text {-int. }}$ & $\begin{array}{l}\text { Longitudinal logistic regression model for repeated measures, using } \\
\text { Generalized Estimating Equations for CAN over 2, 4, 6 and } 8 \text { yrs follow-up }\end{array}$ \\
\hline
\end{tabular}




\begin{tabular}{|c|c|c|c|c|c|}
\hline & $\begin{array}{c}1983-1993 \\
(10 \mathrm{yrs})\end{array}$ & $\begin{array}{l}\text { DD: } 1-15 \text { yrs (all) } \\
\text { Primary prevention } \\
\text { group: } 2.6 \pm 1.4 \text { yrs } \\
\text { Secondary prevention } \\
\text { group: } 8.7 \pm 3.8 \text { yrs } \\
\text { HbA1c: } 74 \mathrm{mmol} / \mathrm{mol}(8.9 \%) \\
\text { TDI: } 0.62-0.71 \pm 0.23 \\
\mathrm{U} / \mathrm{kg} / \text { day respectively } \\
\text { No CAN at baseline }\end{array}$ & $\begin{array}{ll}\text { Every } 3 \text { months } \\
\text { Within-day GV } \\
\text { - } \quad \text { SD glucose } \\
\text { - } \quad \text { MAGE } \\
\text { M-value }\end{array}$ & $\begin{array}{l}\text { Valsalva ratio } \\
\text { Standing: DBP drop } \\
\text { CAN if <predefined cut-offs } \\
\text { on at least one CART } \\
\text { CAN assessment: at baseline } \\
\text { and after 2,4,6,8 years of } \\
\text { follow-up }\end{array}$ & $\begin{array}{l}\rightarrow \text { Unadjusted model: CAN significantly associated with MAGE } \\
\quad\left(p=0.017^{*}\right) \text { and M-value }\left(p=0.046^{*}\right) \\
\rightarrow \text { After adjusting for MBG: None of the measures of } \\
\quad \text { within-day GV (SD glucose, MAGE, M-value) remained significantly } \\
\quad \text { associated with CAN }(p=0.20 ; p=0.06 ; p=0.10)\end{array}$ \\
\hline $\begin{array}{c}\text { Nyiraty et } \\
\text { al. }^{41} \\
(2018)\end{array}$ & $\begin{array}{l}\text { Cross-sectional } \\
(/)\end{array}$ & $\begin{array}{l}n=20 \quad(6 \mathrm{M}, 14 \mathrm{~F}) \\
\text { Age: } 39.5 \pm 3.4 \mathrm{yrs} \\
\text { DD: } 17.5 \pm 2.5 \mathrm{yrs} \\
\text { BMI: } 22.3 \pm 0.8 \\
\text { HbA1c: } 65 \mathrm{mmol} / \mathrm{mol}(8.1 \pm \\
0.7 \%) \\
\text { TDI: } 42.8 \pm 2.9 \mathrm{U} \\
\text { All treated } \mathrm{w} / \mathrm{MDI}\end{array}$ & $\begin{array}{ll}\text { CGM for } 6 \text { days } \\
\text { - } & \text { SD glucose } \\
\text { - } & \text { MAGE } \\
\text { - } & \text { MAG }\end{array}$ & $\begin{array}{l}\frac{\text { CAN \& CAN-sCore }(/ 10)}{\text { based on: } \text { CARTs }} \\
\frac{\text { CARTs }}{\text { Deep breathing: } \triangle H R} \\
\text { Valsalva ratio } \\
\text { Standing: } 30: 15 \text { ratio } \\
\text { Standing: SBP drop } \\
\text { Handgrip: DBP rise } \\
\text { CAN if score } \geq 2 / 10\end{array}$ & 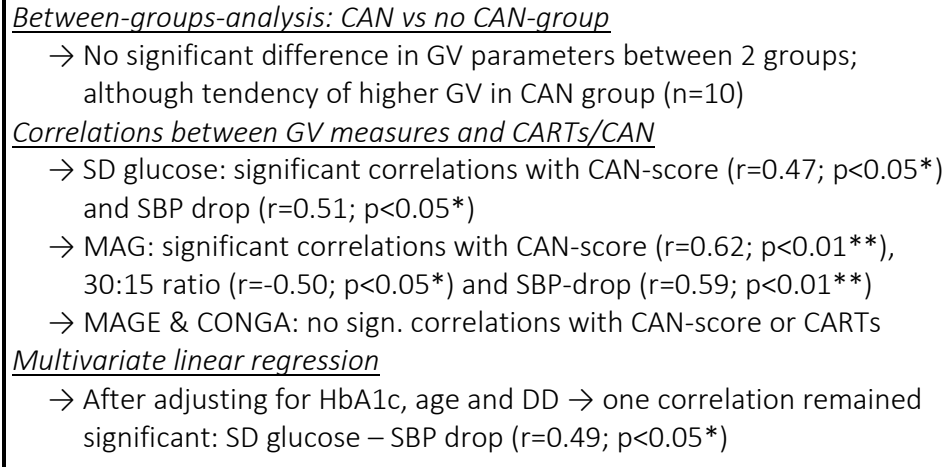 \\
\hline $\begin{array}{l}\text { Jaiswal et al. }{ }^{42} \\
\text { (2018) }\end{array}$ & $\begin{array}{c}\text { Prospective } \\
\text { cohort } \\
\text { (3 yrs) }\end{array}$ & $\begin{array}{l}\mathrm{n}=41 \quad(16 \mathrm{M}, 25 \mathrm{~F}) \\
\text { Age: } 34 \pm 13 \mathrm{yrs} \text { (range:18-65) } \\
\text { DD: } 13 \pm 6 \text { (All DD >5 yrs) } \\
\text { BMl: } 26 \pm 4 \\
\text { HbA1c: } 64 \mathrm{mmol} / \mathrm{ml}(8.0 \pm \\
1.2 \%) \\
\text { TDI: } 0.7 \pm 0.2 \mathrm{U} / \mathrm{kg} / \text { day }\end{array}$ & $\begin{array}{ll}\text { CGM for } 5 \text { days } \\
\text { Every } 3 \text { months } \\
\text { - } \quad \text { COV glucose } \\
\text { - } & \text { MAGE } \\
\text { - } & \text { ABGI \& HBGI } \\
& \text { hypoglycaemia } \\
\text { - } & \text { AUC for } \\
& \text { hyperglycaemia } \\
\end{array}$ & $\begin{array}{l}\text { Blood pressure dipping }(\%) \\
\text { ABPM assessment: every year }\end{array}$ & $\begin{array}{l}\text { Between-groups-analysis at baseline: Non-dipping group ( } n=4) \text { vs Dipping } \\
\text { group ( } n=37) \text { : } \\
\quad \rightarrow \text { No significant differences in GV measures } \\
\text { Correlations at baseline } \\
\quad \rightarrow \text { No significant correlations at baseline between BP dipping-\% and } \\
\quad \text { GV measures } \\
\text { Between-groups-analysis after } 3 \text { yrs: Progressors group }(n=24) \text { vs Non- } \\
\text { progressors group }(n=17): \\
\rightarrow \text { No significant differences in GV measures }\end{array}$ \\
\hline $\begin{array}{c}\text { Jun et al. }{ }^{40} \\
(2018)\end{array}$ & $\begin{array}{c}\text { Cross-sectional } \\
(/)\end{array}$ & $\begin{array}{l}n=80 \quad(35 \mathrm{M}, 45 \mathrm{~F}) \\
\text { Age: } 39.9 \pm 14 \text { yrs }\end{array}$ & $\begin{array}{l}\text { CGM for } 3 \text { days, of which } \\
\text { middle } 48 \text { h used }\end{array}$ & \begin{tabular}{|l} 
CAN - based on: CARTs \\
Deep breathing: El-ratio
\end{tabular} & $\begin{array}{l}\text { Between-groups-analysis: CAN-group }(n=36) \text { vs No CAN-group }(n=44) \text { : } \\
\rightarrow \text { Higher SD }\left(p<0.001^{* * *}\right) \text {, COV }\left(p=0.007^{* *}\right) \text { and MAGE }\left(p=0.003^{* *}\right)\end{array}$ \\
\hline
\end{tabular}




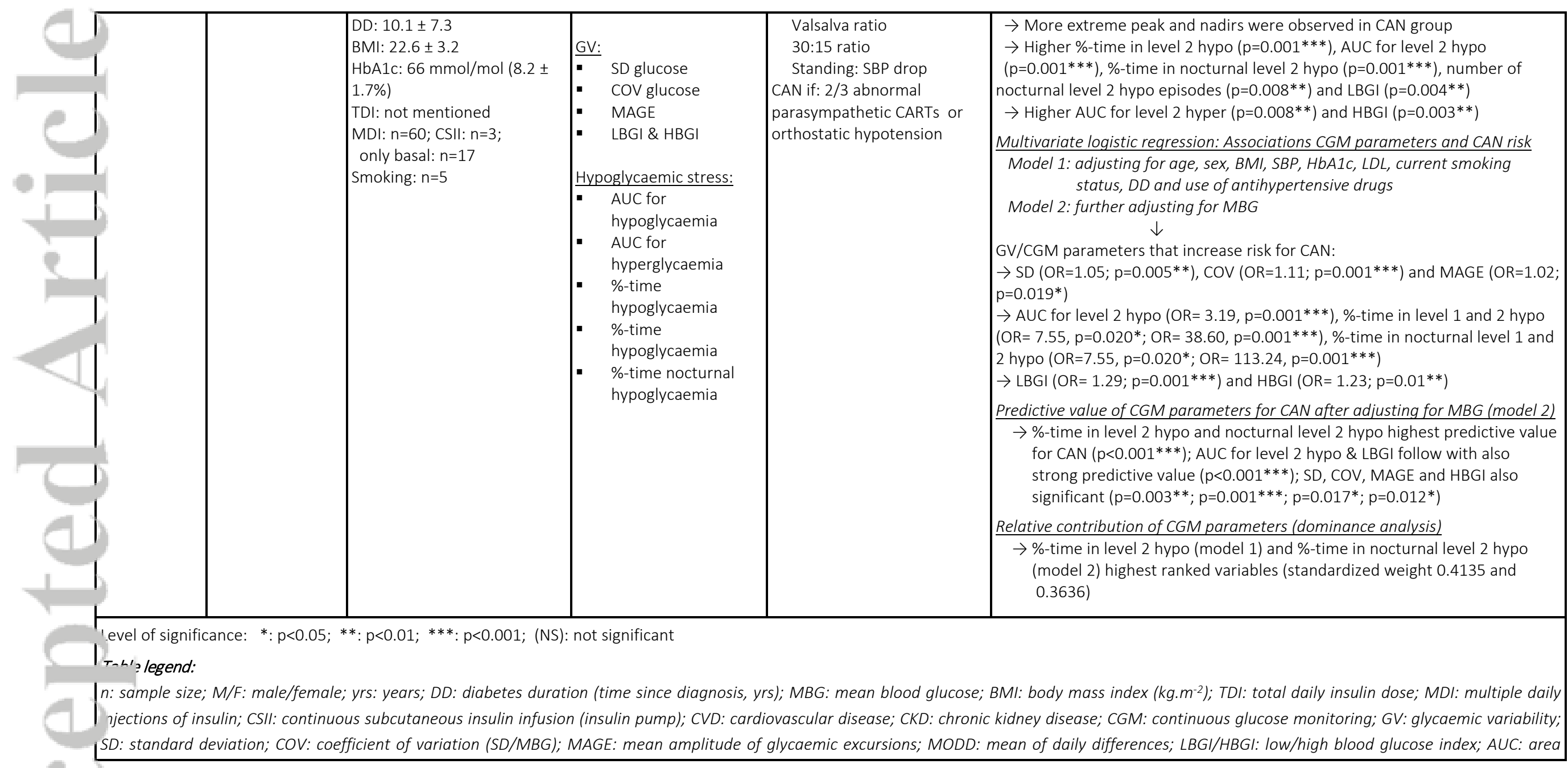


Inder the curve; CAN: cardiac/cardiovascular autonomic neuropathy; HRV: heart rate variability; LF/HF: low/high frequency; CART: cardiovascular autonomic reflex test; E:--ratio: expiration:inspiration-ratio; SBP/DBP: systolic/diastolic blood pressure; ABPM: ambulatory blood pressure monitoring; OR: odds ratio

TABLE 2. Evidence table: Results of included studies assessing the relationship between glycaemic variability and cardiovascular autonomic function in type 1 diabetes.

\begin{tabular}{|c|c|l|}
$\begin{array}{c}\text { First author } \\
\text { Noar of publication) }\end{array}$ & $\begin{array}{c}\text { Study design } \\
\text { (Follow-up) }\end{array}$ & \multicolumn{1}{c|}{ Key findings \& Main conclusions } \\
\hline Jaiswal et al. (2014) ${ }^{39}$ & $\begin{array}{c}\text { Cross-sectional } \\
\text { analysis at baseline }\end{array}$ & $\begin{array}{l}\text { Increased GV promoting hypoglycemic stress is associated with reduced HRV, independent of glycemic control as assessed by HbA1c. } \\
\text { Inverse associations persisted after adjusting for HbA1c but attenuated by age, DD and BMI. }\end{array}$ \\
\hline
\end{tabular}




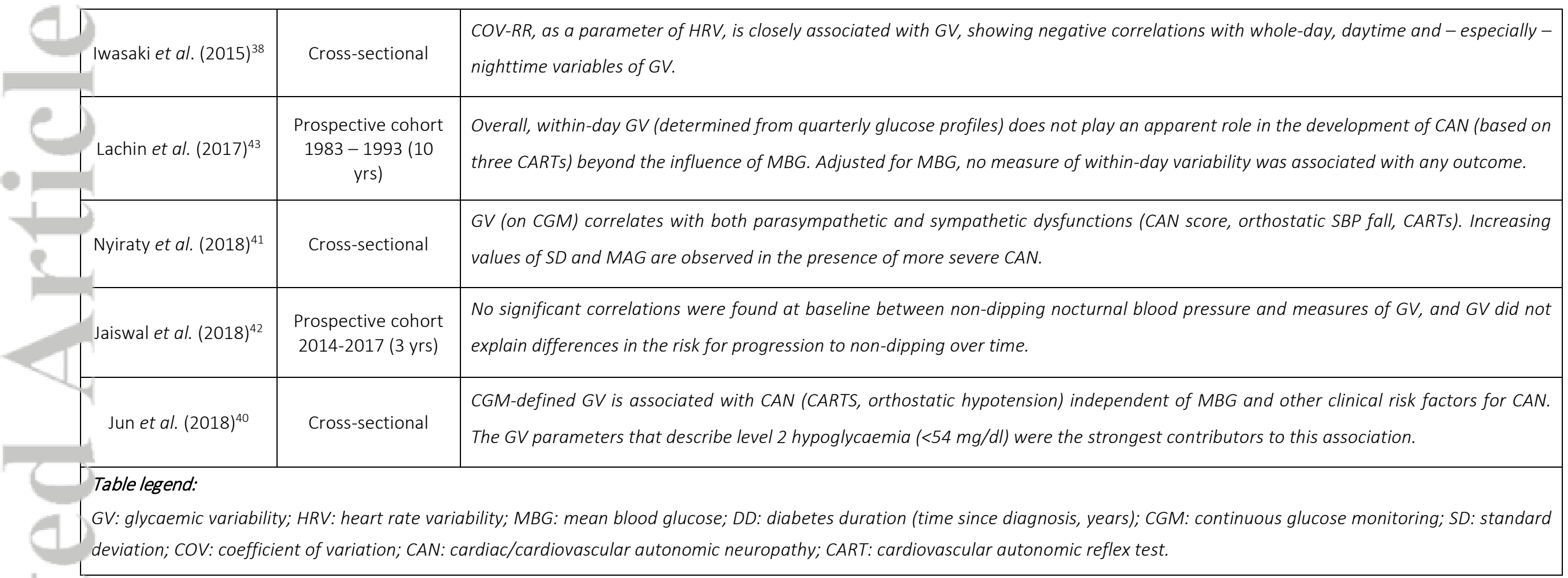

TABLE 3. Main conclusions of included studies. 


\section{The relationship between glycaemic variability and cardiovascular autonomic dysfunction in patients with type 1 diabetes: a systematic review}

S. Helleputte · T. De Backer - B. Lapauw · S. Shadid - B. Celie · B. Van Eetvelde $\cdot$ K. Vanden Wyngaert · P. Calders

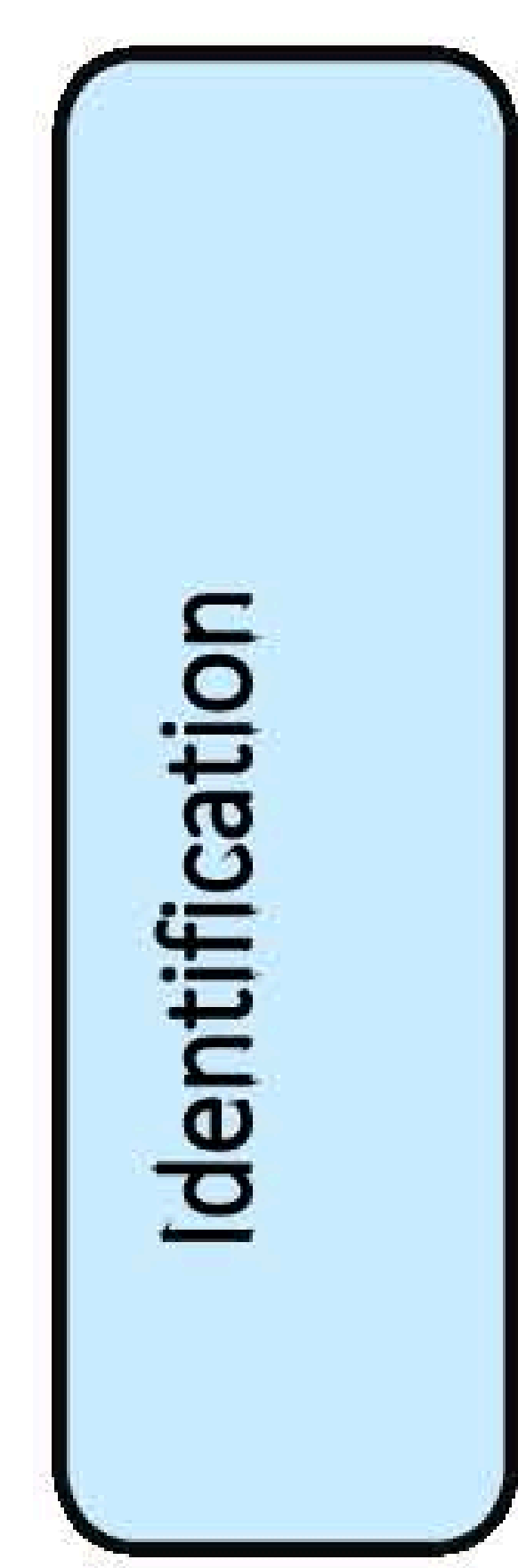

Records identified through database searching $(n=2574)$

Additional records identified through other sources: hand-searching $(n=2)$
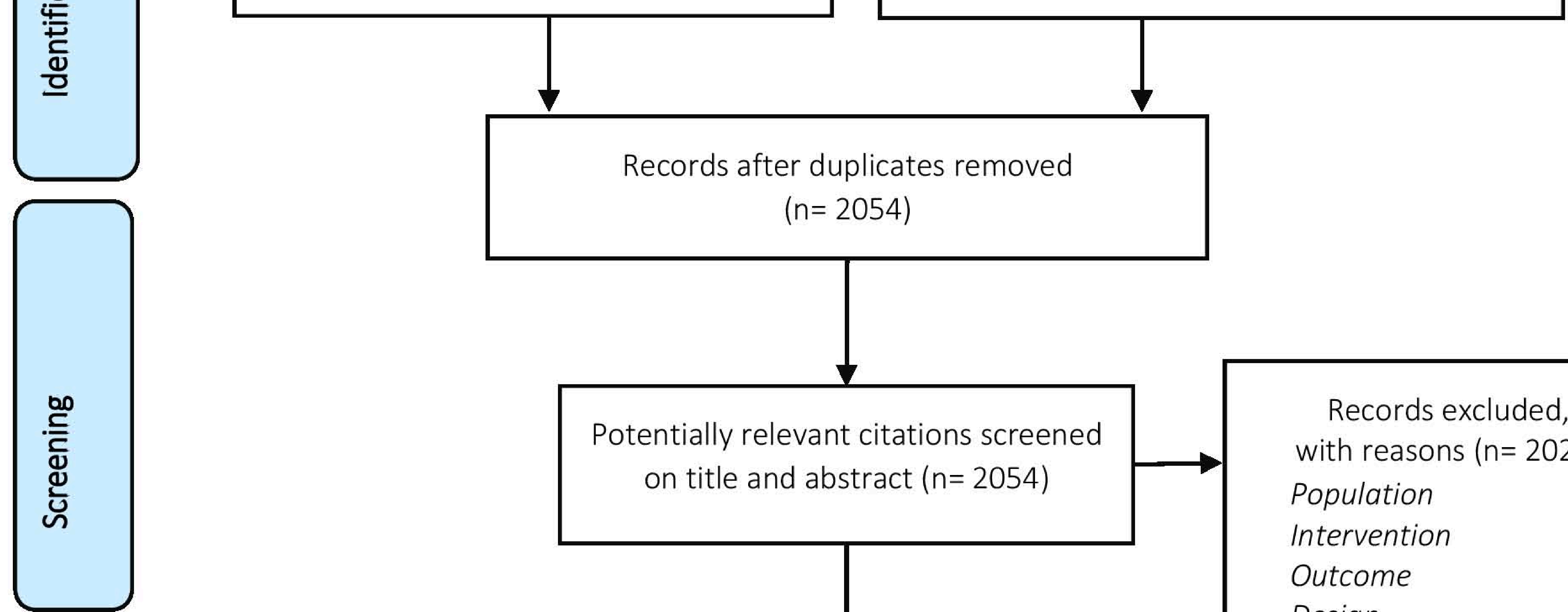

Records after duplicates removed $(n=2054)$

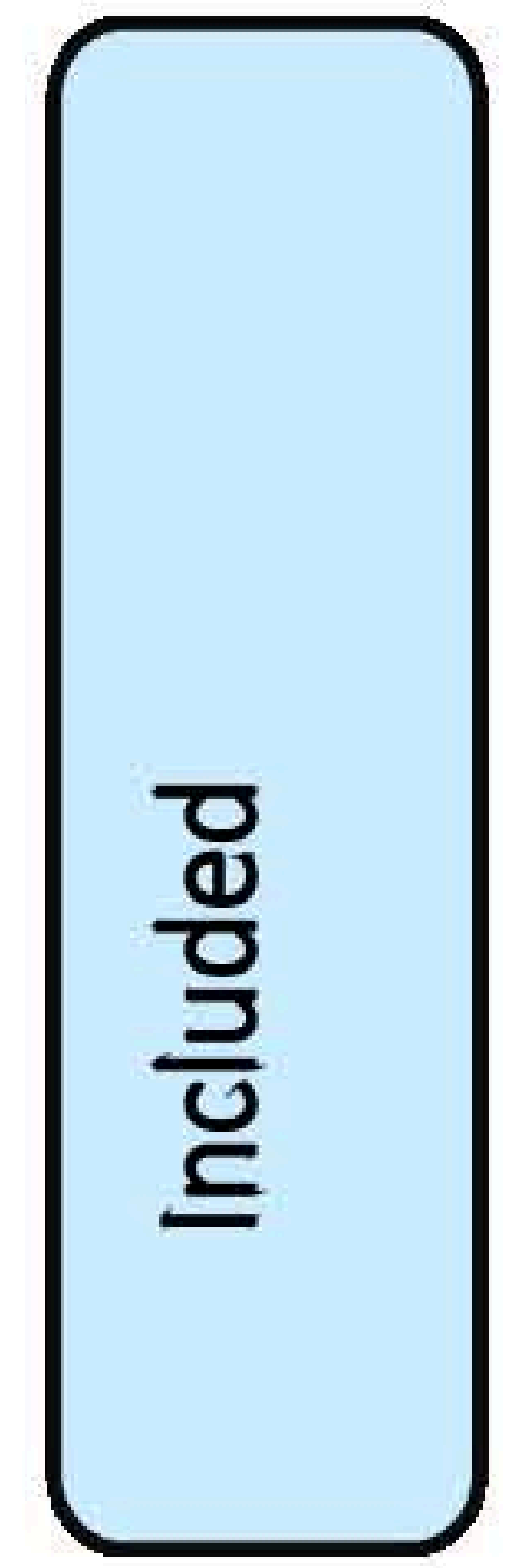

Potentially relevant citations screened on title and abstract $(n=2054)$

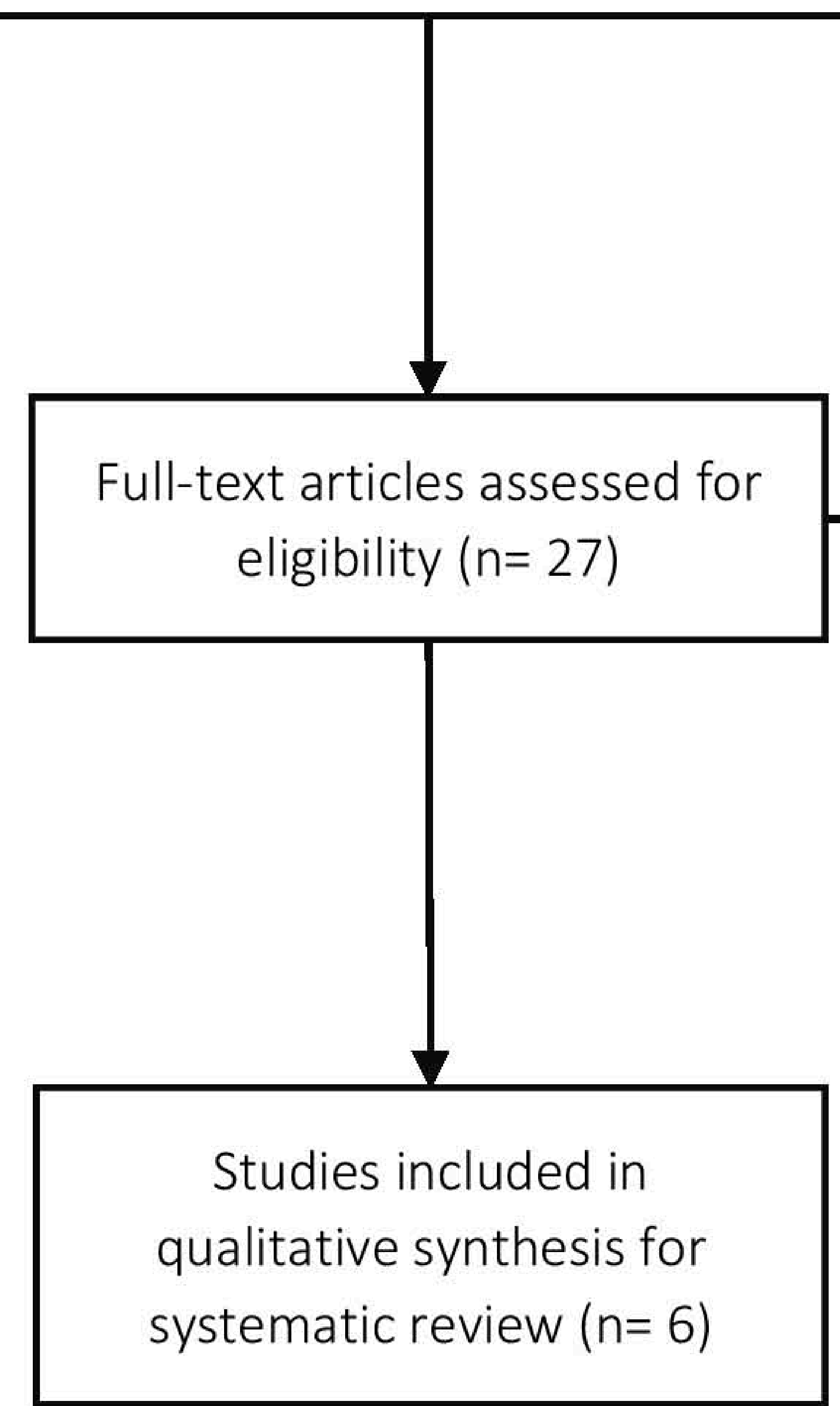

Records excluded, with reasons $(n=2027)$

Population

Intervention $\quad 524$

Outcome 93

Design 102

Language $\quad 27$

Full-text articles excluded, with reasons $(n=21)$

Population 2

Intervention 14

Outcome

Fig. 1. Flowchart study selection. 